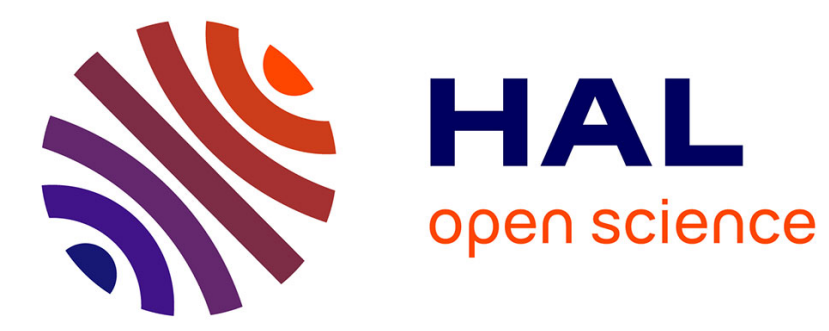

\title{
FeNC catalysts for CO 2 electroreduction to CO: effect of nanostructured carbon supports
}

\author{
Dilan Karapinar, Ngoc-Huan Tran, Domitille Giaume, Nastaran Ranjbar, \\ Frederic Jaouen, Victor Mougel, Marc Fontecave
}

\section{To cite this version:}

Dilan Karapinar, Ngoc-Huan Tran, Domitille Giaume, Nastaran Ranjbar, Frederic Jaouen, et al.. FeNC catalysts for CO 2 electroreduction to CO: effect of nanostructured carbon supports. Sustainable Energy \& Fuels, 2019, 3 (7), pp.1833-1840. 10.1039/c9se00214f . hal-02272815

\section{HAL Id: hal-02272815 \\ https://hal.umontpellier.fr/hal-02272815}

Submitted on 28 Aug 2019

HAL is a multi-disciplinary open access archive for the deposit and dissemination of scientific research documents, whether they are published or not. The documents may come from teaching and research institutions in France or abroad, or from public or private research centers.
L'archive ouverte pluridisciplinaire HAL, est destinée au dépôt et à la diffusion de documents scientifiques de niveau recherche, publiés ou non, émanant des établissements d'enseignement et de recherche français ou étrangers, des laboratoires publics ou privés. 
Check for updates

Cite this: Sustainable Energy Fuels, 2019, 3, 1833

\section{FeNC catalysts for $\mathrm{CO}_{2}$ electroreduction to $\mathrm{CO}$ : effect of nanostructured carbon supports $\uparrow$}

\author{
Dilan Karapinar, (D) a Ngoc-Huan Tran, ${ }^{a}$ Domitille Giaume, (D) ${ }^{\mathrm{b}}$ Nastaran Ranjbar, ${ }^{\mathrm{c}}$ \\ Frédéric Jaouen, ${ }^{c}$ Victor Mougel (DD *a and Marc Fontecave (iD) *a
}

Received 3rd April 2019

Accepted 30th May 2019

DOI: $10.1039 / c 9 s e 00214 f$

rsc.li/sustainable-energy

\begin{abstract}
$\mathrm{CO}_{2}$ electroreduction to $\mathrm{CO}$ is an attractive strategy for using $\mathrm{CO}_{2}$ as a feedstock for the production of organic chemicals. However, there is still a need to develop catalysts based on non-noble metals since the best catalytic systems for that specific reaction are based on silver and gold, in particular when high current densities are required. Iron- and nitrogen-doped carbon materials (FeNC) have recently emerged as cheap, stable and active alternatives, however with still limited current densities. Here we report that both the current density and the selectivity of FeNC-based cathodes can be significantly improved by mixing FeNC with carbon materials such as carbon nanotubes (CNT) or carbon nanofibers (CNF). More specifically, we show that a cathode based on a FeNC-CNF composite material shows $c a$. a twice higher $j_{\mathrm{CO}} / j_{\mathrm{H}_{2}}$ ratio and up to twice higher $j_{\mathrm{CO}}$ value over a broad potential range. The FeNC-CNF electrode compares well with $\mathrm{Ag}$ and $\mathrm{Au}$ electrodes with a very high selectivity for $\mathrm{CO}$ production (FY for $\mathrm{CO}$ of almost 90\%) and current densities above $10 \mathrm{~mA} \mathrm{~cm}^{-2}$ at $-0.7 \mathrm{~V}$ vs. RHE.
\end{abstract}

\section{Introduction}

Energy storage in the form of chemical energy (fuels) has become one of the key technological issues to be addressed urgently in the context of the requested substitution of renewable energies for fossil fuels, as a way to mitigate $\mathrm{CO}_{2}$ emissions. This can be achieved via water electrolysis, generating hydrogen that can subsequently be converted back into electricity within fuel cells, on demand. The electrochemical reduction of $\mathrm{CO}_{2}$ into carbon monoxide, formic acid and various energy-dense hydrocarbons and alcohols is less advanced as a technology but currently is a matter of great research efforts all over the world. ${ }^{1}$ It might provide opportunities to use $\mathrm{CO}_{2}$ as a raw carbon source for the synthesis of industrial chemicals. All $\mathrm{CO}_{2}$ reduction reactions, involving multi-electron and multi-proton processes, are kinetically challenging and thus request the development of cheap, stable and efficient catalysts.

A number of metal-based catalysts currently used in electrolyzers and fuel cells are associated with carbon-based materials. Carbon is a cheap and abundant material with excellent electronic conductivity, relatively inert surface which can be

${ }^{a}$ Laboratoire de Chimie des Processus Biologiques, UMR CNRS 8229, Collège de France, CNRS, Sorbonne Université, 11 Place Marcelin Berthelot, 75005 Paris, France.E-mail: marc.fontecave@college-de-france.fr; mougel@inorg.chem.ethz.ch

${ }^{b}$ Chimie Paris Tech, PSL Research University, CNRS, Institut de Recherche de Chimie de Paris, 11 rue Pierre et Marie Curie, 75005 Paris, France

'Institut Charles Gerhardt Montpellier, UMR CNRS 5253, Université Montpellier, 2 place Eugène Bataillon, 34095 Montpellier, France

$\dagger$ Electronic supplementary information (ESI) available. See DOI: 10.1039/c9se00214f obtained with high surface area. Carbon materials are particularly effective as supports for metal nanoparticles allowing high dispersion even at high wt\% loading and often resulting in an improvement of their activity and stability. For example, Pt nanoparticles of 2-3 nm supported on high surface area carbon, called $\mathrm{Pt} / \mathrm{C}$, is one of the most effective catalytic material at the cathode of fuel cells for the oxygen reduction reaction (ORR). ${ }^{2}$ Another interesting characteristic of using carbon materials as a support for a catalyst or in composite mixtures with the catalyst is that they are available in a variety of forms with different properties and aspect ratios. While carbon black has been used most often until now, heterogeneous metal-based ORR catalysts have in recent years been associated with carbon nanotubes in either single-walled (SWCNT) or multiwalled (MWCNT) forms, and with graphene or reduced graphene oxide (rGO), because of their unique electronic conductivity, extremely high surface area, high mechanical strength and improved chemical inertness. This association has resulted in significant improvement of catalyst performances. ${ }^{3}$

In contrast, very few studies comparing the effects of various carbon supports on the performances of catalysts for $\mathrm{CO}_{2}$ reduction $\left(\mathrm{CO}_{2} \mathrm{R}\right)$ have been reported so far. This is surprising considering that most current $\mathrm{CO}_{2} \mathrm{R}$ catalysts still suffer from low product selectivity, large electrochemical overpotential requirements, low current density and low $\mathrm{CO}_{2}$ conversion. Some studies have concerned Fe nanoparticles, ${ }^{4}$ but most of the work has been done aiming at comparing the activities and selectivities of $\mathrm{Cu}$ nanoparticles deposited on various carbon supports, namely conventional carbon blacks (Vulcan, Ketjen black), SWCNTs, rGO, carbon nanospikes and onion-like 
carbon (OLC). ${ }^{5}$ Cu-based materials are indeed extensively studied as $\mathrm{CO}_{2} \mathrm{R}$ catalysts since they are unique in catalyzing the reduction of $\mathrm{CO}_{2}$ up to methane and multicarbon compounds such as ethylene. ${ }^{1}$ These studies revealed the large influence of the carbon supports notably on the selectivity of deposited $\mathrm{Cu}$ nanoparticles and on the onset potentials for the various products. Remarkable faradaic yields (FY) as high as $60 \%$ for ethylene were obtained with $\mathrm{Cu} / \mathrm{OLC} .{ }^{5 c} \mathrm{~A}$ recent study expanded the repertoire of carbon supports for $\mathrm{Cu}$ nanoparticles to carbon frameworks derived from the pyrolysis of butterfly-wings and reported a FY for ethylene of almost $64 \%$, one of the highest value reported for a $\mathrm{CO}_{2} \mathrm{R}$ catalyst so far. ${ }^{6}$

Another emerging class of promising $\mathrm{CO}_{2} \mathrm{R}$ catalysts based on earth-abundant metals is that of MNC materials in which isolated transition metal atoms (e.g. $\mathrm{M}=\mathrm{Ni}, \mathrm{Fe}$ or $\mathrm{Co}$ ) are atomically dispersed in nitrogen-doped graphite-like materials and present a $\mathrm{MN}_{4}$ in-plane coordination with nitrogen atoms in the first coordination sphere, reminiscent of that existing in metal-porphyrin and phthalocyanine complexes. ${ }^{7}$ Robust synthesis methods to produce such materials were reported and, specifically, NiNC and FeNC were shown to be the most efficient catalysts in this class of materials for the reduction of $\mathrm{CO}_{2}$ to $\mathrm{CO}$, rivaling Au- and Ag-based catalysts in faradaic efficiency. ${ }^{7 b, 7 i}$ A recent survey of catalysts for $\mathrm{CO}_{2}$ to $\mathrm{CO}$ conversion highlighted that fact and stressed that FeNC was among the most promising non noble metal catalysts, based on selectivity and overpotential requirement criteria. ${ }^{8}$ However, FeNC-based cathodes still present lower current densities than bulk noble metal catalysts (Au notably), limiting their potential applicability for industrial processes. Thus, FeNC catalysts deserve further improvement studies with the aim of using them in energy storage technological devices in the future.

While enhancing the number of active sites in FeNC catalysts may appear as an obvious approach to increase the $\mathrm{CO}_{2} \mathrm{R}$ current density, we recently established that low Fe contents in FeNC materials were essential to ensure high selectivity for CO. We indeed demonstrated that, above an Fe content threshold, FeNC materials prepared via pyrolysis contain not only $\mathrm{FeN}_{4}$ sites but also $\mathrm{Fe}$ nanoparticles, the latter displaying high selectivity for $\mathrm{H}_{2}$ evolution (HER), while the isolated $\mathrm{FeN}_{4}$ sites were shown to be the actual sites for selective CO formation. ${ }^{7 c}$

Another approach for enhancing the kinetics of the reaction aims at reducing mass transport limitations, which are key factors in the overall current density due to the low solubility of $\mathrm{CO}_{2}$ in aqueous solution. We hence reasonned that mixing FeNC catalysts with high surface area carbon materials could be an appropriate strategy for improving the cathode structure, and hence for increasing $\mathrm{CO}_{2} \mathrm{R}$ current densities. However, such an approach is not necessarily straightforward in the context of $\mathrm{CO}_{2}$ reduction, as it has been observed in several instances that carbon supports, especially with high surface areas, might significantly degrade the selectivity of the catalyst, notably via the promotion of the competing HER reaction. ${ }^{9}$

Here we provide the first report aiming at comparing the effects of different carbon supports, namely reduced graphene oxide (rGO), multiwall carbon nanotubes (MWCNT) and carbon nanofibers (CNF), on the performances (activity and selectivity) of FeNC materials as catalysts for $\mathrm{CO}_{2}$ reduction to $\mathrm{CO}$. The FeNC-carbon composites were prepared simply via mixing FeNC with the various carbon material additives. This led us to identify carbon nanofibers as a unique carbon material additive for FeNC, allowing both higher $\mathrm{CO}_{2} \mathrm{R}$ current densities and higher selectivity for $\mathrm{CO}$ formation than those of any previously reported FeNC-based cathodes.

\section{Results}

\section{Preparation and characterization of the electrodes}

The FeNC material was prepared, as previously described, from a mixture of Zn-based zeolitic imidazolate framework (ZIF-8), ferrous acetate and phenanthroline, which was submitted to flash pyrolysis under flowing $\mathrm{Ar}$ at $1050{ }^{\circ} \mathrm{C} .{ }^{7} \mathrm{We}$ chose a loading of $0.5 \mathrm{wt} \%$ of $\mathrm{Fe}$ in the precursor mixture, as we previously showed that, under those conditions, a catalyst containing isolated $\mathrm{FeN}_{4}$ sites exclusively was formed. ${ }^{7 c}$ Different inks were obtained by dispersing $10 \mathrm{mg}$ of FeNC in a Nafion ${ }^{\circledR}$ suspension in the absence or in the presence of $1 \mathrm{mg}$ rGO, MWCNT or CNF. Electrodes were then prepared by depositing the inks on a gas diffusion layer (GDL) followed by a drying step as described in the Experimental section. The resulting FeNC-carbon electrodes, thus containing $10 \mathrm{mg}$ FeNC and $1 \mathrm{mg}$ carbon material additive fully deposited on $1 \mathrm{~cm}^{2} \mathrm{GDL}$, are named FeNC, FeNCrGO, FeNC-CNT and FeNC-CNF respectively in the following. Control electrodes were prepared by deposition of $1 \mathrm{mg}$ of carbon nanomaterials on $1 \mathrm{~cm}^{2} \mathrm{GDL}$, without FeNC, are named rGO, CNT and CNF. The Fe content was assessed by Inductively Coupled Plasma-Atomic Emission Spectrometry (ICP-AES) and found to be, within experimental error, comparable in all FeNCbased electrodes, even though a slightly larger Fe content was found in FeNC-CNF (Table S1†). This could be due to the larger porosity of carbon nanofibers as compared to other carbon supports.

The electrodes prepared by deposition of the carbon materials on the GDL, FeNC-free (Fig. S1 $\dagger$ ) or mixed with FeNC (Fig. 1), were analyzed by Scanning Electron Microscopy (SEM). The SEM images showed a homogeneous deposition of the various materials at the surface of the GDL support. Scanning Electron Microscopy/Energy Dispersive Spectroscopy (SEM/ EDS) confirmed the presence of $\mathrm{Fe}, \mathrm{N}$ and $\mathrm{C}$ at the surface of the electrode materials (Fig. S2 and S3†), and that the original FeNC material (present as ca. $500 \mathrm{~nm}$ nanoparticles) are preserved and well dispersed on the support. ${ }^{10}$ In contrast, no $\mathrm{Fe}$ and $\mathrm{N}$ atoms could be detected in rGO, CNT and CNF samples as well as in bare GDL (Fig. S2 and S3†). An elemental mapping analysis is provided in the case of FeNC-CNF (Fig. S2 $\uparrow$ ), showing homogeneous distribution of $\mathrm{Fe}$ and $\mathrm{N}$ elements within the sample (Fig. S2†).

Finally, in line with the nanostructuration of the carbon supports, measurements of the electrochemical active surface areas (ECSA) of the various electrodes showed much larger surfaces areas in the case of FeNC-rGO, FeNC-CNT and FeNC$\mathrm{CNF}$, ranging from 4 to $5.5 \mathrm{~cm}^{2} / \mathrm{cm}^{2}$, as compared to $\mathrm{FeNC}$ (Fig. 1d, S4 and S5†). 
a)

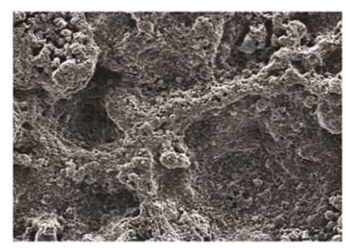

$\overline{100 \mu \mathrm{m}}$

b)

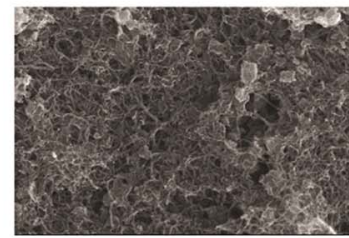

$200 \mathrm{~nm}$

c)

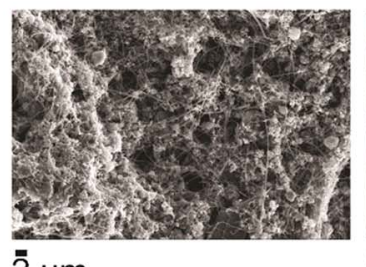

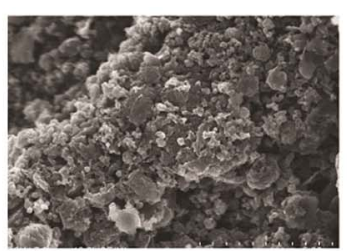

$\overline{5} \mu \mathrm{m}$

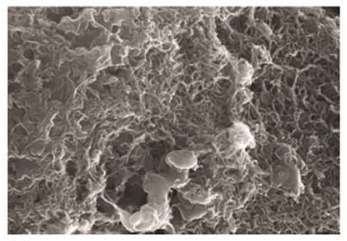

$\overline{2} 00 \mathrm{~nm}$

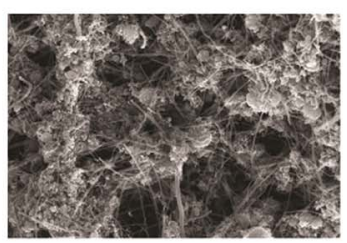

$1 \mu \mathrm{m}$

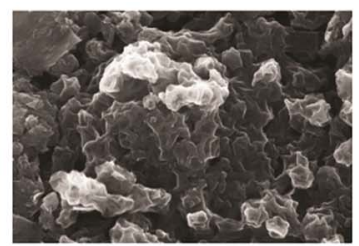

$\overline{1} \mu \mathrm{m}$

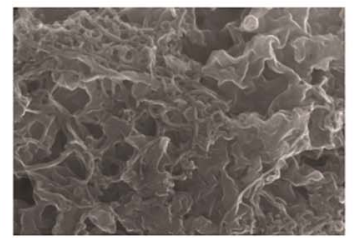

$100 \mathrm{~nm}$

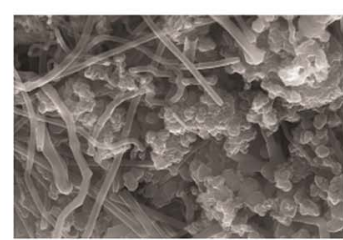

$200 \mathrm{~nm}$

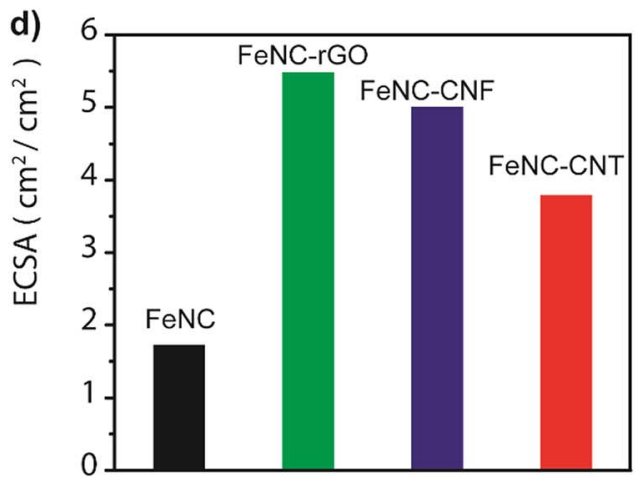

Fig. 1 SEM images of (a) FeNC-rGO, (b) FeNC-CNF and (c) FeNC-CNT deposited on GDL electrodes, (d) electrochemically active surface areas (ECSA) of the electrodes, determined as described in the Experimental section, expressed as $\mathrm{cm}^{2} / \mathrm{cm}^{2}$ electrode.

\section{Electrocatalytic $\mathrm{CO}_{2} \mathrm{R}$ activity of FeNC-carbon materials}

Electroreduction of $\mathrm{CO}_{2}$ catalyzed by the FeNC-carbon composite materials was first investigated by linear sweep voltammetry (LSV) in $\mathrm{CO}_{2}$-saturated $0.1 \mathrm{M}$ aqueous solutions of various alkali bicarbonates ( $\mathrm{Na}, \mathrm{K}, \mathrm{Cs}$ ), in the potential range of 0.0 to $-1.2 \mathrm{~V} v s$. RHE. Linear sweep voltammograms (LSVs) under these conditions are reported in Fig. S6. $\dagger$ They showed a drastic effect of the cation of the electrolyte on the $\mathrm{CO}_{2} \mathrm{R}$ activity of all FeNC-based catalysts, the current density increasing as a function of the cation size in the order $\mathrm{Na}^{+}<\mathrm{K}^{+}<\mathrm{Cs}^{+}$, in agreement with previous reports. ${ }^{11}$ Based on this observation and on previous work, we chose to use $0.1 \mathrm{M} \mathrm{CsHCO}_{3}$ as the electrolyte in this study. Its relatively low cost, in particular as the electrolyte is not consumed in the electrocatalytic reaction, makes it a relevant choice even for a future large industrial use.

LSV data in $0.1 \mathrm{M} \mathrm{CsHCO}_{3}$ are collected in Fig. S7. $\dagger$ They clearly illustrate that all tested FeNC-carbon composite materials generated larger current densities than those obtained with the different carbon materials without FeNC (Fig. S8†). Furthermore, in agreement with their higher ECSA, the FeNC-carbon composites immobilized on GDL generated higher current densities at any tested potential than FeNC immobilized on GDL, thus in the order FeNC $<$ FeNC-rGO $<$ FeNC-CNF $<$ FeNC-CNT.

We then characterized the $\mathrm{CO}_{2} \mathrm{R}$ catalytic activity of the various materials by controlled-potential electrolysis (CPE) at potentials ranging from -0.4 to $-1.0 \mathrm{~V} v s$. RHE in a $0.1 \mathrm{M}$ $\mathrm{CsHCO}_{3}$ aqueous solution under $10 \mathrm{~mL} \mathrm{~min}{ }^{-1}$ flow of $\mathrm{CO}_{2}$. In all cases, $\mathrm{CO}$ and $\mathrm{H}_{2}$ were the only reaction products. No other gaseous products, such as methane or multicarbon compounds, and no liquid products, such as formic acid or alcohols, could be detected. The results are shown in Fig. 2 and S9-S11. $\dagger$ Fig. S9 $\dagger$ aimed at confirming that also under electrolysis the highest current densities were obtained using $0.1 \mathrm{M}$ $\mathrm{CsHCO}_{3}$ as the electrolyte. Fig. S10 $\uparrow$ shows that, in the absence 
a)

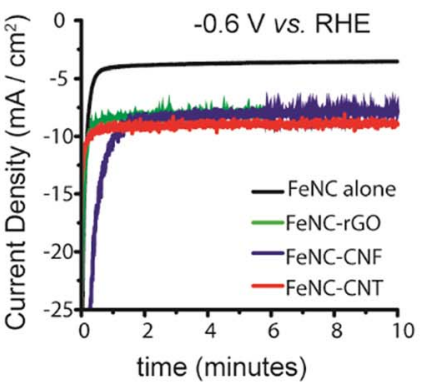

b)

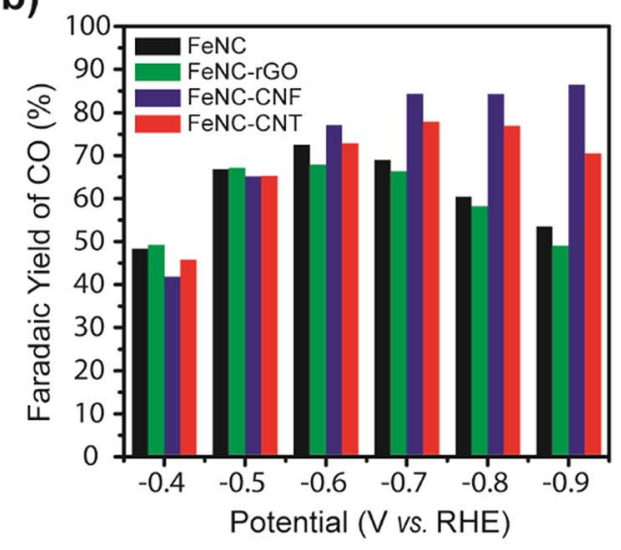

d)

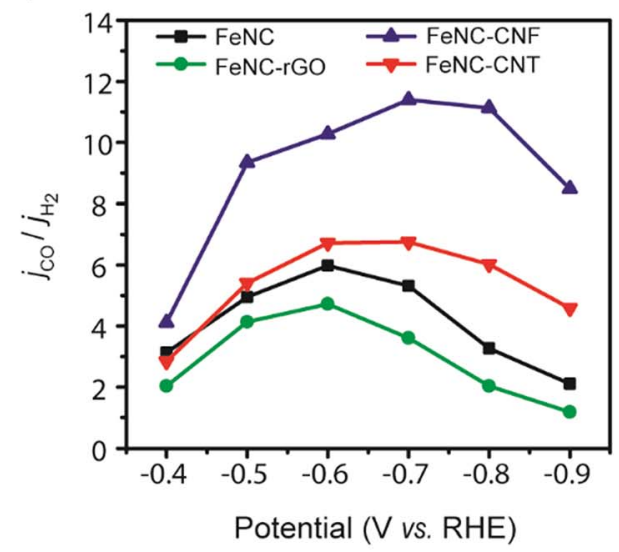

$-0.7 \vee v s$. RHE

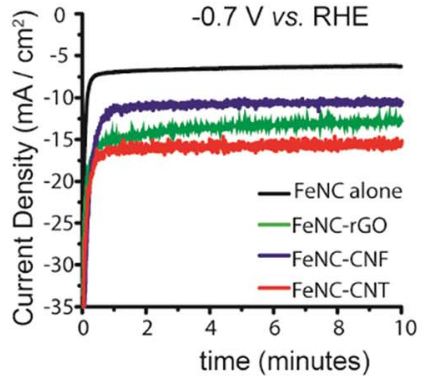

c)

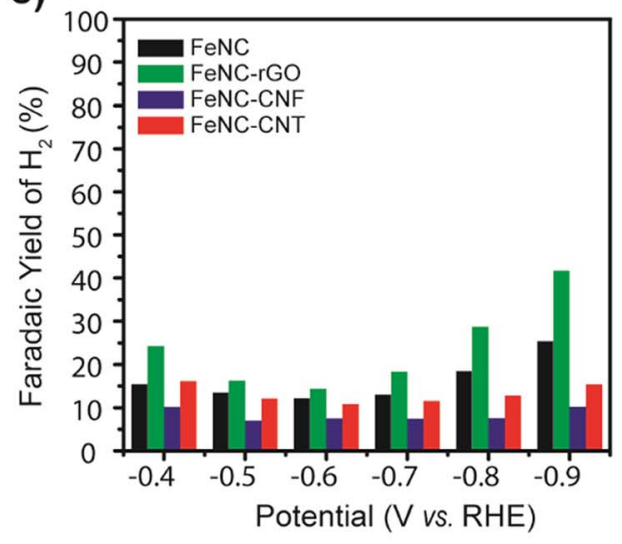

e)

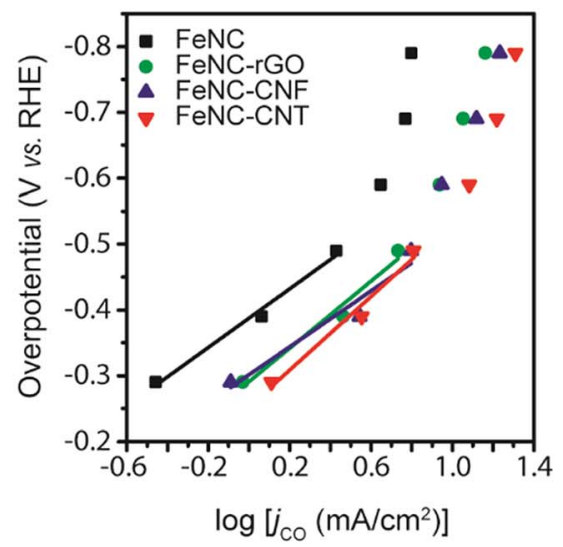

Fig. 2 Total current density during electrolysis at various applied potentials (a) faradaic yields of (b) $\mathrm{CO}$ and (c) $\mathrm{H}_{2}$ after 10 min electrolysis; (d) partial current densities of $\mathrm{CO}$ production over $\mathrm{H}_{2}$ production after 10 min electrolysis; (e) plot of overpotential as a function of logarithmic partial current density for $\mathrm{CO}$ production. In all graphs: FeNC (black), FeNC-rGO (green), FeNC-CNF (blue), and FeNC-CNT (red). All CPE experiments were run in a $0.1 \mathrm{M} \mathrm{CsHCO}_{3}$ aqueous solution under $10 \mathrm{~mL} \mathrm{~min}{ }^{-1}$ flow of $\mathrm{CO}_{2}$.

of FeNC catalyst, all carbon supports, rGO, CNF, and CNT, deposited on GDL did not show any activity for $\mathrm{CO}_{2}$ reduction in the studied potential range, generating exclusively $\mathrm{H}_{2}$. This clearly shows that $\mathrm{CO}$ formation is exclusively due to the FeNC component of the composite materials.

The data in Fig. 2 and S10 $\dagger$ showed that, in agreement with LSVs, all FeNC-carbon catalysts generated at any applied potential much higher current densities than FeNC immobilized directly on the GDL and than the same carbon materials in the absence of FeNC (compare Fig. 2 and S10†). In terms of current densities, FeNC-CNT surpassed other materials in the order FeNC-CNT $>$ FeNC-rGO $>$ FeNC-CNF $>$ FeNC with current densities ranging from $25 \mathrm{~mA} \mathrm{~cm}^{-2}$ (FeNC-CNT) to $17 \mathrm{~mA} \mathrm{~cm}^{-2}$ (FeNC-CNF) at $-0.8 \mathrm{~V} v$ s. RHE or from $17 \mathrm{~mA} \mathrm{~cm}^{-2}$ (FeNC-CNT) to $12 \mathrm{~mA} \mathrm{~cm}{ }^{-2}$ (FeNC-CNF) at $-0.7 \mathrm{~V} v s$. RHE (Fig. 2a).

Selectivity did not follow the same trend: FeNC-CNF proved the most selective catalyst for $\mathrm{CO} v s . \mathrm{H}_{2}$ production, followed by FeNC-CNT, while FeNC-rGO was much better at catalyzing proton reduction (Fig. $2 \mathrm{~b}$ and c). The highest $\mathrm{CO}$ production (FY for $\mathrm{CO}$ up to $84 \%$ ) was obtained with FeNC-CNF at $-0.7 \mathrm{~V} v s$. RHE (Fig. 2b). These differences in selectivity are better illustrated in Fig. $2 \mathrm{~d}$ which plots the $j_{\mathrm{Co}} / j_{\mathrm{H}_{2}}$ ratio, in which $j_{x}$ is the 
partial current density for the production of compound $x$, as a function of the applied potential. Absolute values of $j_{\mathrm{CO}}$ and $j_{\mathrm{H}_{2}}$ are reported in Fig. S11. $\uparrow$ Remarkably, in the case of FeNCCNF a large $j_{\mathrm{CO}} / j_{\mathrm{H}_{2}}$ value, between 8 and 10, was achieved over a broad range of potentials, between -0.6 and $-0.9 \mathrm{~V} v s$. RHE (Fig. 2d). In comparison, FeNC immobilized directly on the GDL gave a $j_{\mathrm{CO}} / j_{\mathrm{H}_{2}}$ value of 6 at best, as previously reported (Fig. $2 \mathrm{~d}$ ). ${ }^{7 c}$

Tafel plots reporting partial current densities for $\mathrm{CO}$ production as a function of over-potentials are displayed in Fig. 2e. They allow the determination of Tafel slopes as well as onset potentials for CO formation (Table $\mathrm{S} 2 \dagger$ ). All samples are characterized by a Tafel slope of about $200 \mathrm{mV} \mathrm{dec}^{-1}$, quite far from the $120 \mathrm{mV} \mathrm{dec}{ }^{-1}$ expected for a rate-limiting step corresponding to the first electron transfer and with an exchange transfer coefficient of circa 0.5. On the other hand, it is interesting to note that all three FeNC-carbon composite materials immobilized on GDL catalyzed $\mathrm{CO}_{2}$ to $\mathrm{CO}$ reduction with onset potentials less cathodic of $80-120 \mathrm{mV}$ than that of FeNC directly immobilized on GDL.

Finally, to assess the stability of the best FeNC-carbon composite materials during $\mathrm{CO}_{2}$ reduction, a $12 \mathrm{~h}$ electrolysis experiment was performed at $-0.7 \mathrm{~V} v s$. RHE using FeNC-CNF and FeNC-CNT as the catalysts, under a continuous 10 $\mathrm{mL} \min ^{-1}$ flow of $\mathrm{CO}_{2}$. As shown in Fig. 3, the current density remained stable at $c a .12 \mathrm{~mA} \mathrm{~cm}{ }^{-2}$ for FeNC-CNF and $17.5 \mathrm{~mA}$ $\mathrm{cm}^{-2}$ for FeNC-CNT during the whole experiment and the selectivity for $\mathrm{CO}_{2}$ vs. $\mathrm{H}^{+}$reduction did not change with time, with $\mathrm{FY}=85 \%$ and $77 \%$ for FeNC-CNF and FeNC-CNT, respectively. Furthermore, SEM images and EDS analyses at the end of the electrolysis confirmed the stability of the catalysts with respect to their structure (Fig. S12 and S13†).

\section{Discussion}

We recently established that FeNC, a cheap and stable graphitic material doped with nitrogen and iron, containing isolated porphyrin-like $\mathrm{FeN}_{4}$ sites, is a promising catalyst for the electroreduction of $\mathrm{CO}_{2}$ to $\mathrm{CO}$ with good selectivity for $\mathrm{CO}$ (faradaic yields of about $75 \%$ ) at rather low overpotential. Nevertheless, the current densities obtained with that material were still lower than those of metallic gold or silver electrodes. Here we show that the performances of FeNC-based cathodes can be greatly improved by mixing it with nanostructured carbon materials such as carbon nanotubes (CNT) or carbon nanofibers (CNF), providing catalytic materials with significantly increased surface areas (Fig. 1). Remarkably, the resulting increased current densities in both cases were obtained together with parallel increased selectivities for CO, with FeNC-CNF giving excellent FY for CO of almost $90 \%$ at $-0.7 \mathrm{~V} v$ s. RHE. As shown from the $j_{\mathrm{CO}} / j_{\mathrm{H}_{2}}$ parameter, shifting from about 6 for FeNC to 10 for FeNC-CNF, the CNF support provides FeNC with a greater $\mathrm{CO}_{2}$ reduction reactivity as compared to proton reduction. In addition, high CO selectivity was observed within a broader range of potentials than the original material. While FeNC-CNT gives higher current densities than FeNC-CNF, it stands between FeNC and FeNC-CNF in terms of FY for CO.

Very often, it is observed that increased current densities are obtained at the expense of decreased selectivity. This is for example the case here when mixing reduced graphene oxide (rGO) with FeNC, since FeNC-rGO, while more efficient (greater current densities) than FeNC, unfortunately generates much more $\mathrm{H}_{2}$. Thus, the strategy used here for optimizing FeNC catalysts for $\mathrm{CO}_{2}$ reduction has been successful as, in the case of FeNC-CNT and FeNC-CNF, we improved efficiency and selectivity at the same time. In addition, we show here that these new materials are structurally and functionally stable during electrolysis (Fig. 3).

This is remarkable as CNTs and CNFs are known to often contain metallic ( $\mathrm{Fe}, \mathrm{Co}, \mathrm{Ni}, \mathrm{Cu}$ ) impurities which may have electrocatalytic activities towards proton reduction to $\mathrm{H}_{2}$ and thus may degrade the selectivity of supported catalysts for $\mathrm{CO}_{2}$ reduction. ${ }^{12}$

Several parameters are likely to play a role in the enhancement of the catalytic activity (current densities and selectivities) of the FeNC-carbon composite materials: (i) the excellent electrical conductivity of CNTs and CNFs allows for a more efficient charge collection and transfer to the $\mathrm{FeN}_{4}$ active sites and decreases junction and resistance overpotentials; (ii) the higher surface area and macroporosity allows to decrease the concentration overpotential by improving both the number of a)

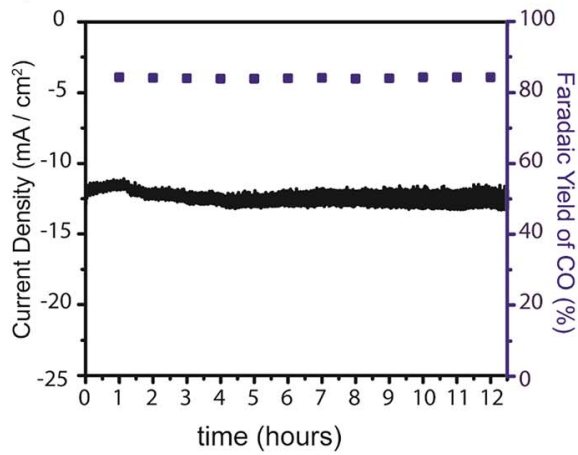

b)

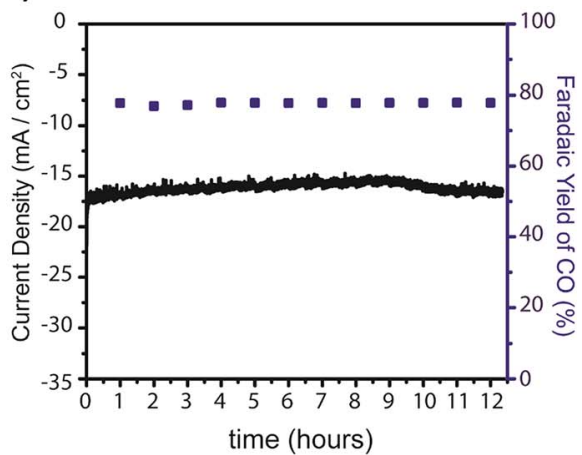

Fig. 3 Current densities during CPE and faradaic yield of CO: (a) FeNC-CNF and (b) FeNC-CNT under $10 \mathrm{~mL} \mathrm{~min}^{-1}$ flow of CO in a $0.1 \mathrm{M}$ $\mathrm{CsHCO}_{3}$ aqueous solution at potentials at $-0.7 \mathrm{~V} v$ s. RHE for 12 hours. 
accessible sites and the convection/diffusion of the electrolyte through the electrode; (iii) the increased hydrophobicity environment provided by the carbon additives to the FeNC catalyst allows an increased $\mathrm{CO}_{2} / \mathrm{H}^{+}$ratio at the surface active sites, thus favoring $\mathrm{CO}_{2}$ over $\mathrm{H}^{+}$reduction and increasing the resulting selectivity for $\mathrm{CO}_{2}$ conversion to $\mathrm{CO}$. The higher selectivity observed with FeNC-CNF with respect to FeNC-CNT likely originates from the different morphologies of these supports. CNF surfaces are made up from graphene plane edges while CNT surfaces from cylindrical basal planes; thus CNF displays greater microporosity as well as higher electrical charge at the surface. ${ }^{13}$ As a consequence, more efficient mass transfer at the triple phase interface and charge transfer are expected.

\section{Conclusion}

FeNC, in which Fe atoms are dispersed in nitrogen-doped graphite-like materials, are good catalysts for $\mathrm{CO}_{2}$ electroreduction to $\mathrm{CO}$. Here we show that FeNC can greatly benefit from being combined with highly conductive and hydrophobic carbon nanomaterials with large specific surface area. In particular, when mixed with carbon nanofibers, they catalyze $\mathrm{CO}_{2}$ electroreduction with larger current densities and larger selectivity for CO production, leading to one of the most efficient and selective catalytic materials based on non-noble metals. ${ }^{8}$

\section{Materials and methods}

\section{Materials}

FeNC material was prepared according to previously reported procedures. ${ }^{7 c}$ Carbon fiber paper (AVCarb GDS 3250) was used as a gas diffusion layer. It has a thickness of $225 \mu \mathrm{m}$ and a through-plane resistivity lower than $14.0 \mathrm{mohm} \mathrm{cm}^{2}$. Reduced graphene oxide (rGO), carbon nanofibers (iron-free) (CNFs) and multi-walled carbon nanotubes (CNTs) supports were acquired from Sigma-Aldrich. CNTs and CNFs were used after acid treatment. The raw carbon materials were dispersed in concentrated $\mathrm{H}_{2} \mathrm{SO}_{4}$ and sonicated for $4 \mathrm{~h}$ and then washed repeatedly with deionized water until the $\mathrm{pH}$ value got close to 7. They were finally dried in a vacuum oven at $85{ }^{\circ} \mathrm{C}$ overnight. ${ }^{14}$

\section{Electrode preparation}

For FeNC-CNT preparation, $10 \mathrm{mg}$ of the catalyst material and $1 \mathrm{mg}$ pre-treated CNT were sonicated for $2 \mathrm{~h}$ in $400 \mu \mathrm{L}$ of isopropyl alcohol and $5 \mu \mathrm{L}$ of a Nafion ${ }^{\circledR}$ perfluorinated resin solution (5 wt\% in mixture of lower aliphatic alcohols and water, containing $5 \%$ water). Then, the whole suspension was deposited by drop-casting (one drop every 30 seconds) on a GDL $\left(1 \mathrm{~cm}^{2}\right)$ and dried in air at $100{ }^{\circ} \mathrm{C}$ for 30 minutes. The same protocol was used for the preparation of FeNC-rGO and FeNC$\mathrm{CNF}$ electrodes. As for the preparation of the control electrodes without FeNC, $1 \mathrm{mg}$ of the carbon material was sonicated in 200 $\mu \mathrm{L}$ of isopropyl alcohol and $5 \mu \mathrm{L}$ of a Nafion® perfluorinated resin solution, then whole suspension was deposited on GDL (1 $\mathrm{cm}^{2}$ ).

\section{Electrode characterization}

Scanning electron microscopy (SEM) images were acquired using a Hitachi S-4800 scanning electron microscope. Iron contents within catalytic materials were quantified with ICPAES in a Thermo Scientific iCAP 6300 duo device after digestion of the graphitic structures in a $3: 1 \mathrm{H}_{2} \mathrm{SO}_{4}$ (96\% wt pure)$\mathrm{HNO}_{3}(56 \%$ wt pure) acid mixture, followed by filtration.

\section{Electrochemical characterization}

All electrochemical measurements were performed in a threeelectrode two-compartment cell using a Bio-logic SP300 potentiostat, with a reference electrode, namely $\mathrm{Ag} / \mathrm{AgCl} / 3 \mathrm{M} \mathrm{KCl}$ (hereafter abbreviated as $\mathrm{Ag} / \mathrm{AgCl}$ ), placed in the same compartment as the working electrode $\left(1 \mathrm{~cm}^{2}\right.$ geometric area). A platinum counter electrode was placed in a separate compartment. The two compartments were separated by a membrane (Fumasep-Bipolar Membrane). The electrolyte was $\mathrm{CO}_{2}$-saturated $0.1 \mathrm{M} \mathrm{CsHCO}_{3}$. The electrochemical cell was first purged with $\mathrm{CO}_{2}$ at a flow rate of $25 \mathrm{~mL} \mathrm{~min}^{-1}$ during one hour prior to catalytic tests, and then, during electrolysis, continuously purged with $\mathrm{CO}_{2}$ at a fixed flow rate using a mass flow controller (Bronkhorst EL-FLOW model F-201CV). All electrochemical data was referenced to RHE using the following equation: $E(\mathrm{~V} v s$. $\mathrm{RHE})=E(\mathrm{~V} v s . \mathrm{Ag} / \mathrm{AgCl})+E(\mathrm{~V}$ of $\mathrm{Ag} / \mathrm{AgCl} v s . \mathrm{NHE})+0.059 \times$ $\mathrm{pH}$, with $E(\mathrm{~V}$ of $\mathrm{Ag} / \mathrm{AgCl} v s$. NHE $)=0.205 \mathrm{~V}$ and a $\mathrm{pH}$ value of 6.8 for the electrolyte. The effluent gas products from the electrochemical cell were identified and quantified using a gas chromatograph (SRI 8610C) equipped with a packed Molecular Sieve 5 Å column for permanent gases separation and a packed Haysep-D column for light hydrocarbons separation. Argon (Linde 5.0) was used as carrier gas. A flame ionization detector (FID) coupled to a methanizer was used to quantify CO, methane and hydrocarbons while a thermal conductivity detector (TCD) was used to quantify $\mathrm{H}_{2}$. Liquid phase products were quantified by ${ }^{1} \mathrm{H}$ NMR spectroscopy (Bruker AVANCE III $300 \mathrm{MHz}$ spectrometer using a Pre-SAT180 water suppression method $^{15}$ ). Samples were prepared by mixing a $300 \mu \mathrm{L}$ aliquot of electrolyte solution with $50 \mu \mathrm{L} \mathrm{D}_{2} \mathrm{O}$ used for NMR-locking and $10 \mu \mathrm{L}$ of acetonitrile used as internal standard $(1 \mu \mathrm{mol})$. Formic acid was analyzed by ionic exchange chromatography (883 Basic IC, Metrohm).

\section{Electrochemically active surface area measurements}

Real surface areas of the different electrodes were estimated by probing the redox reaction of the ferricyanide/ferrocyanide couple using cyclic voltammetry (CV). $0.1 \mathrm{M} \mathrm{KCl}$ solution containing $10 \mathrm{mM}$ ferrocyanide was initially degassed with Ar. Then the potential of the working electrode was swept between $600 \mathrm{mV}$ and $-200 \mathrm{mV} v s$. $\mathrm{Ag} / \mathrm{AgCl}(1 \mathrm{M} \mathrm{KCl})$ at different scan rates $\left(\mathrm{mV} \mathrm{s}^{-1}\right)$. Between each $\mathrm{CV}$ at different rates, the solution was bubbled with Ar and stirred to quickly reach back to the initial conditions. Electrochemically active surface areas (ECSA) were estimated from the Randles-Sevcik equation, as follows: $I_{\mathrm{p}}$ $=\left(2.69 \times 10^{5}\right) n^{3 / 2} A D^{1 / 2} \nu^{1 / 2} C$, with $I_{\mathrm{p}}$ : peak current, $n$ : number of moles of electrons per mole of electroactive species, $A$ : area of 
electrode $\left(\mathrm{cm}^{2}\right), D$ : diffusion coefficient $\left(\mathrm{cm}^{2} \mathrm{~s}^{-1}\right), \nu$ : scan rate $\left(\mathrm{V} \mathrm{s}^{-1}\right), C$ : concentration $\left(\mathrm{mol} \mathrm{cm}{ }^{-3}\right)$. The diffusion coefficient of ferricyanide is $6.7 \times 10^{-6} \mathrm{~cm}^{2} \mathrm{~s}^{-1}$ and its concentration $10^{-5} \mathrm{~mol} \mathrm{~cm}^{-3}$. The ECSA (A) is estimated from the slope of the plot of $I_{\mathrm{p}}$ versus $\nu^{1 / 2}$.

\section{Conflicts of interest}

There are no conflicts to declare.

\section{Acknowledgements}

D. K. acknowledges support from Fondation de l'Orangerie for individual Philanthropy and its donors.

\section{References}

1 (a) J. Qiao, Y. Liu, F. Hong and J. Zhang, A review of catalysts for the electroreduction of carbon dioxide to produce lowcarbon fuels, Chem. Soc. Rev., 2014, 43(2), 631-675; (b) L. Zhang, Z.-J. Zhao and J. Gong, Nanostructured Materials for Heterogeneous Electrocatalytic $\mathrm{CO}_{2}$ Reduction and their Related Reaction Mechanisms, Angew. Chem., Int. Ed., 2017, 56(38), 11326-11353; (c) W. Zhang, Y. Hu, L. Ma, G. Zhu, Y. Wang, X. Xue, R. Chen, S. Yang and Z. Jin, Progress and Perspective of Electrocatalytic $\mathrm{CO}_{2}$ Reduction for Renewable Carbonaceous Fuels and Chemicals, $A d v$. Sci., 2018, 5(1), 1700275.

2 J. Liu, C.-T. Liu, L. Zhao, J.-J. Zhang, L.-M. Zhang and Z.-B. Wang, Effect of different structures of carbon supports for cathode catalyst on performance of direct methanol fuel cell, Int. J. Hydrogen Energy, 2016, 41(3), 1859-1870.

3 J.-C. Li, D.-M. Tang, P.-X. Hou, G.-X. Li, M. Cheng, C. Liu and H.-M. Cheng, The effect of carbon support on the oxygen reduction activity and durability of single-atom iron catalysts, MRS Commun., 2018, 8(3), 1158-1166.

4 (a) C. Genovese, C. Ampelli, S. Perathoner and G. Centi, Electrocatalytic conversion of $\mathrm{CO}_{2}$ on carbon nanotubebased electrodes for producing solar fuels, J. Catal., 2013, 308, 237-249; (b) C. Genovese, C. Ampelli, S. Perathoner and G. Centi, Electrocatalytic conversion of $\mathrm{CO}_{2}$ to liquid fuels using nanocarbon-based electrodes, J. Energy Chem., 2013, 22(2), 202-213.

5 (a) O. A. Baturina, Q. Lu, M. A. Padilla, L. Xin, W. Li, A. Serov, K. Artyushkova, P. Atanassov, F. Xu, A. Epshteyn, T. Brintlinger, M. Schuette and G. E. Collins, $\mathrm{CO}_{2}$ Electroreduction to Hydrocarbons on Carbon-Supported $\mathrm{Cu}$ Nanoparticles, ACS Catal., 2014, 4(10), 3682-3695; (b) Y. Song, R. Peng, D. K. Hensley, P. V. Bonnesen, L. Liang, Z. Wu, H. M. Meyer III, M. Chi, C. Ma, B. G. Sumpter and A. J. Rondinone, High-Selectivity Electrochemical Conversion of $\mathrm{CO}_{2}$ to Ethanol using a Copper Nanoparticle/N-Doped Graphene Electrode, ChemistrySelect, 2016, 1(19), 6055-6061; (c) O. Baturina, Q. Lu, F. Xu, A. Purdy, B. Dyatkin, X. Sang, R. Unocic, T. Brintlinger and Y. Gogotsi, Effect of nanostructured carbon support on copper electrocatalytic activity toward $\mathrm{CO}_{2}$ electroreduction to hydrocarbon fuels, Catal. Today, 2017, 288, 2-10.

6 Y. Huo, X. Peng, X. Liu, H. Li and J. Luo, High Selectivity Toward $\mathrm{C}_{2} \mathrm{H}_{4}$ Production over $\mathrm{Cu}$ Particles Supported by Butterfly-Wing-Derived Carbon Frameworks, ACS Appl. Mater. Interfaces, 2018, 10(15), 12618-12625.

7 (a) A. S. Varela, N. Ranjbar Sahraie, J. Steinberg, W. Ju, H.-S. Oh and P. Strasser, Metal-Doped Nitrogenated Carbon as an Efficient Catalyst for Direct $\mathrm{CO}_{2}$ Electroreduction to $\mathrm{CO}$ and Hydrocarbons, Angew. Chem., Int. Ed., 2015, 54(37), 10758-10762; (b) W. Ju, A. Bagger, G.-P. Hao, A. S. Varela, I. Sinev, V. Bon, B. Roldan Cuenya, S. Kaskel, J. Rossmeisl and P. Strasser, Understanding activity and selectivity of metal-nitrogen-doped carbon catalysts for electrochemical reduction of $\mathrm{CO}_{2}$, Nat. Commun., 2017, 8(1), 944; (c) T. N. Huan, N. Ranjbar, G. Rousse, M. Sougrati, A. Zitolo, V. Mougel, F. Jaouen and M. Fontecave, Electrochemical Reduction of $\mathrm{CO}_{2}$ Catalyzed by $\mathrm{Fe}-\mathrm{N}-\mathrm{C}$ Materials: A Structure-Selectivity Study, ACS Catal., 2017, 7(3), 1520-1525; (d) C. Zhao, X. Dai, T. Yao, W. Chen, X. Wang, J. Wang, J. Yang, S. Wei, Y. Wu and Y. Li, Ionic Exchange of Metal-Organic Frameworks to Access Single Nickel Sites for Efficient Electroreduction of $\mathrm{CO}_{2}$, J. Am. Chem. Soc., 2017, 139(24), 8078-8081; (e) X. Li, W. Bi, M. Chen, Y. Sun, H. Ju, W. Yan, J. Zhu, X. Wu, W. Chu, C. $\mathrm{Wu}$ and Y. Xie, Exclusive $\mathrm{Ni}-\mathrm{N}_{4}$ Sites Realize Near-Unity CO Selectivity for Electrochemical $\mathrm{CO}_{2}$ Reduction, J. Am. Chem. Soc., 2017, 139(42), 14889-14892; (f) K. Jiang, S. Siahrostami, T. Zheng, Y. Hu, S. Hwang, E. Stavitski, Y. Peng, J. Dynes, M. Gangisetty, D. Su, $\mathrm{K}$. Attenkofer and $\mathrm{H}$. Wang, Isolated $\mathrm{Ni}$ single atoms in graphene nanosheets for high-performance $\mathrm{CO}_{2}$ reduction, Energy Environ. Sci., 2018, 11(4), 893-903; $(g)$ F. Pan, H. Zhang, K. Liu, D. Cullen, K. More, M. Wang, Z. Feng, G. Wang, G. Wu and Y. Li, Unveiling Active Sites of $\mathrm{CO}_{2}$ Reduction on Nitrogen-Coordinated and Atomically Dispersed Iron and Cobalt Catalysts, ACS Catal., 2018, 8(4), 3116-3122; (h) X. Wang, Z. Chen, X. Zhao, T. Yao, W. Chen, R. You, C. Zhao, G. Wu, J. Wang, W. Huang, J. Yang, X. Hong, S. Wei, Y. Wu and Y. Li, Regulation of Coordination Number over Single Co Sites: Triggering the Efficient Electroreduction of $\mathrm{CO}_{2}$, Angew. Chem., Int. Ed., 2018, 57(7), 1944-1948; (i) X.-M. Hu, H. H. Hval, E. T. Bjerglund, K. J. Dalgaard, M. R. Madsen, M.-M. Pohl, E. Welter, P. Lamagni, K. B. Buhl, M. Bremholm, M. Beller, S. U. Pedersen, T. Skrydstrup and K. Daasbjerg, Selective $\mathrm{CO}_{2}$ Reduction to $\mathrm{CO}$ in Water using Earth-Abundant Metal and Nitrogen-Doped Carbon Electrocatalysts, ACS Catal., 2018, 8(7), 6255-6264; (j) J.-J. Shi, X.-M. Hu, M. R. Madsen, P. Lamagni, E. T. Bjerglund, S. U. Pedersen, T. Skrydstrup and K. Daasbjerg, Facile Synthesis of Ironand Nitrogen-Doped Porous Carbon for Selective $\mathrm{CO}_{2}$ Electroreduction, ACS Appl. Nano Mater., 2018, 1(7), 36083615 .

8 D. U. Nielsen, X.-M. Hu, K. Daasbjerg and T. Skrydstrup, Chemically and electrochemically catalysed conversion of 
$\mathrm{CO}_{2}$ to $\mathrm{CO}$ with follow-up utilization to value-added chemicals, Nat. Catal., 2018, 1(4), 244-254.

9 A. Wuttig and Y. Surendranath, Impurity Ion Complexation Enhances Carbon Dioxide Reduction Catalysis, ACS Catal., 2015, 5(7), 4479-4484.

10 V. Armel, J. Hannauer and F. Jaouen, Effect of ZIF-8 Crystal Size on the $\mathrm{O}_{2}$ Electro-Reduction Performance of Pyrolyzed Fe-N-C Catalysts, Catalysts, 2015, 5(3), 1333-1351.

11 (a) A. Murata and Y. Hori, Product Selectivity Affected by Cationic Species in Electrochemical Reduction of $\mathrm{CO}_{2}$ and $\mathrm{CO}$ at a $\mathrm{Cu}$ Electrode, Bull. Chem. Soc. Jpn., 1991, 64(1), 123-127; (b) M. R. Thorson, K. I. Siil and P. J. A. Kenis, Effect of Cations on the Electrochemical Conversion of $\mathrm{CO}_{2}$ to CO, J. Electrochem. Soc., 2013, 160(1), F69-F74; (c) M. R. Singh, Y. Kwon, Y. Lum, J. W. Ager and A. T. Bell, Hydrolysis of Electrolyte Cations Enhances the Electrochemical Reduction of $\mathrm{CO}_{2}$ over $\mathrm{Ag}$ and $\mathrm{Cu}, \mathrm{J} . \mathrm{Am}$. Chem. Soc., 2016, 138(39), 13006-13012; (d) J. Resasco, L. D. Chen, E. Clark, C. Tsai, C. Hahn, T. F. Jaramillo, K. Chan and A. T. Bell, Promoter Effects of Alkali Metal
Cations on the Electrochemical Reduction of Carbon Dioxide, J. Am. Chem. Soc., 2017, 139(32), 11277-11287.

12 (a) C. Ge, W. Li, Y. Li, B. Li, J. Du, Y. Qiu, Y. Liu, Y. Gao, Z. Chai and C. Chen, Significance and Systematic Analysis of Metallic Impurities of Carbon Nanotubes Produced by Different Manufacturers, J. Nanosci. Nanotechnol., 2011, 11(3), 2389-2397; (b) T. Kolodiazhnyi and M. Pumera, Towards an Ultrasensitive Method for the Determination of Metal Impurities in Carbon Nanotubes, Small, 2008, 4(9), 1476-1484.

13 J. Zhu, A. Holmen and D. Chen, Carbon Nanomaterials in Catalysis: Proton Affinity, Chemical and Electronic Properties, and their Catalytic Consequences, ChemCatChem, 2013, 5(2), 378-401.

14 L. Zhao, Z.-B. Wang, X.-L. Sui and G.-P. Yin, Effect of multiwalled carbon nanotubes with different specific surface areas on the stability of supported Pt catalysts, $J$. Power Sources, 2014, 245, 637-643.

15 H. Mo and D. Raftery, Pre-SAT180, a simple and effective method for residual water suppression, J. Magn. Reson., 2008, 190(1), 1-6. 